\title{
INTEGRATED DESIGN MANAGEMENT SYSTEM FOR IMPROVING EFFECTIVE DESIGN COOPERATION THROUGH DOCUMENTATION
}

\author{
ChoongWan Koo \\ HanmiParsons Co., Ltd. CSRI, Seoul, Korea \\ cwkoo@hanmiparsons.com \\ SangHyuk Park \\ HanmiParsons Co., Ltd. CSRI, Seoul, Korea \\ parksh@hanmiparsons.com \\ JaeWon Shin \\ HanmiParsons Co., Ltd. CSRI, Seoul, Korea \\ jwshin@hanmiparsons.com \\ O Kyung Kwon \\ HanmiParsons Co., Ltd. CSRI, Seoul, Korea \\ okkwon@hanmiparsons.com
}

\begin{abstract}
Construction industry consists of many stakeholders and is becoming more complex and interactive. Especially, design phases have a great effect on the efficiency of construction life cycle. Unsystematic and qualitative design management has made it more difficult to accurately manage design stages. To solve this problem, this study developed Integrated Design Management System (IDMS), which is designed to flexibly accommodate change of the construction process, based on the definitions of both design information and relationship between stakeholders. IDMS has been developed under the following conditions: (i) defining the design work process including design works, input information, and output information, (ii) defining the person in charge, weight and checklist on each design works related to design management indices, (iii) incorporating owner requirements into the system to support the decision making process, (iv) uploading design documentation on IDMS as the design process progresses, thus design management indices such as manpower, schedule, quality and approval could be created automatically. This system can be implemented in actual design projects and make a more user-centered design atmosphere.
\end{abstract}

KEYWORDS: integrated design management system, design work process, design documentation, design cooperation.

\section{INTRODUCTION}

\section{Background and purpose}

Construction industry consists of several stages, various stakeholders and a range of technology. It is also growing bigger, more complex and interactive. Especially, design stages 
have a great effect on the project efficiency through construction life cycle (Bae et al 2006). Any decision-making in the design stage is directly related to the succeeding processes such as delivery or construction phase.

Architecture design is a phase of planning a tangible building on a tangible land through intangible work. Due to this characteristic of design work, approval of design documents is considered the primary management index as the final outcome in the conventional design management process (Shin et al. 2007). However, the actual individual steps of design work process were excluded from management elements. As a result, design work was completely depended on the abilities and experiences of each architect rather than organizational and cooperative system. This unsystematic and qualitative design management has made it more difficult to accurately manage design stages as well as improve the competitiveness of the whole project.

As projects are getting more complicated and more stakeholders are getting involved, documentation is becoming more important as a means of intercommunication (Tzortzopoulos et al. 1999). Although a systematic approach for documentation is one of the most critical success factors, the majority of design companies could not adopt such a system due to financial difficulties. However, some large design firms have introduced a systematic approach to managing the design work, but only at an introduction level. Also, in terms of retaining design data, the system was adopted based on personal computers rather than webbased system.

In an effort to help many companies manage design process more systematically, Integrated Design Management System (IDMS) was developed based on the definitions of both design information and relationship between stakeholders. The developed IDMS first sets standards according to the design process, then accumulates the final output as the design process progresses and finally, design management indices such as manpower management, schedule management, quality management and approval management are created automatically.

\section{Scope and methodology}

According to Korea Institute of Construction Technology (KICT 2000), design management refers to a series of the process, including composing a design team to carry out the design work, analyzing details of design work, arranging role-sharing and collaboration procedure and preparing other standards for design process.

Based on the definition by KICT (2000), IDMS has been developed under the following conditions: (i) defining the design work process including design works, input information, and output information, (ii) defining the person in charge, weight and checklist on each design works related to design management indices, (iii) incorporating owner requirements into the system to support the decision making process, (iv) uploading design documentation on IDMS as the design process in progress, thus design management indices such as manpower, schedule, quality and approval could be created automatically. The research process is as follows:

(1) Practical design management process is figured out through interviews with design management experts and the design management indices that need to be controlled at the design stages of the project are analyzed through the interview. 
(2) Standards for design process are established through interviews with relevant experts. Design process consists of document breakdown structure, weight and checklist on each design works, cooperation document and plan for the schedule.

(3) Integrated Design Management System (IDMS) is developed based on the research results as mentioned above, which is validated through interviews with relevant experts.

This IDMS is being developed as a system, thus will be used in the implementation process of actual design projects and make a more user-centered design atmosphere.

\section{LITERATURE REVIEW}

\section{Integrated design process}

In an integrated project, the project flow from conceptualization through implementation and closeout differs significantly from a non-integrated project. Moving design decisions upstream as far as possible to where they are more effective and less costly suggests a rethinking of typical project phases (AIA 2007 (a)). Construction Users Roundtable (CURT) has illustrated the concept of making design decisions earlier in the project through MacLeamy Curve

MacLeamy Curve conceptually illustrates the relation between the ability to impact cost and functional capabilities and cost of design changes. In other words, it is clearly stated through these graphs that making design decisions earlier in the project, when opportunity to influence positive outcomes is maximized and the cost of changes minimized, is very important especially from the designers' and design consultants' point of view.

\section{Early stakeholder involvement}

Design decision making in IPD process is placed at an earlier stage compared to the traditional process as aforementioned. As design decision making is shifted forward, design process should be redefined as follows: (i) conceptualization; (ii) criteria design; (iii) detailed design; (iv) implementation documents; (v) agency review; (vi) buyout; (vii) construction, (viii) closeout. Also, several input data need to be produced and integrated earlier from various stakeholders such as constructors, suppliers and fabricators as well as designers. A comparison of traditional delivery and integrated delivery is presented in AIA 2007 (b), focusing on the shifts of both when different parts of the project are resolved (What, How, Who, Realize) and when different participants of the project become involved.

These concepts in earlier project stages boast a higher level of completion than the traditional process. Thus, the first three phases in the integrated process, which consists of conceptualization, criteria design and detailed design, needs to be involved with more effort than the traditional delivery methods. This higher level of completion at earlier project stage means that the succeeding phase, Implementation Document, requires less effort, produces more efficient performance and enables a potentially shorter construction period than the traditional Construction Documents phase. 


\section{SYSTEM ARCHITECTURE AND RELATIONSHIP}

IDMS provides the following functions: (i) Project Setting, (ii) Owner Cooperation Management, (iii) Design Document Management, (iv) Time Report, (v) Schedule Management, (vi) Quality Management, (vii) Approval Document Management, (viii) Community. Several stakeholders such as Owner, Design Manager, Designer and Engineer (Structure, Mech., Elec. Communication., Landscaping, Civil) could be authorized to utilize IDMS as a design management tool. Functional composition of IDMS is shown in Fig. 1. More detailed description regarding each individual module of IDMS is shown in Fig. 2 and 3.

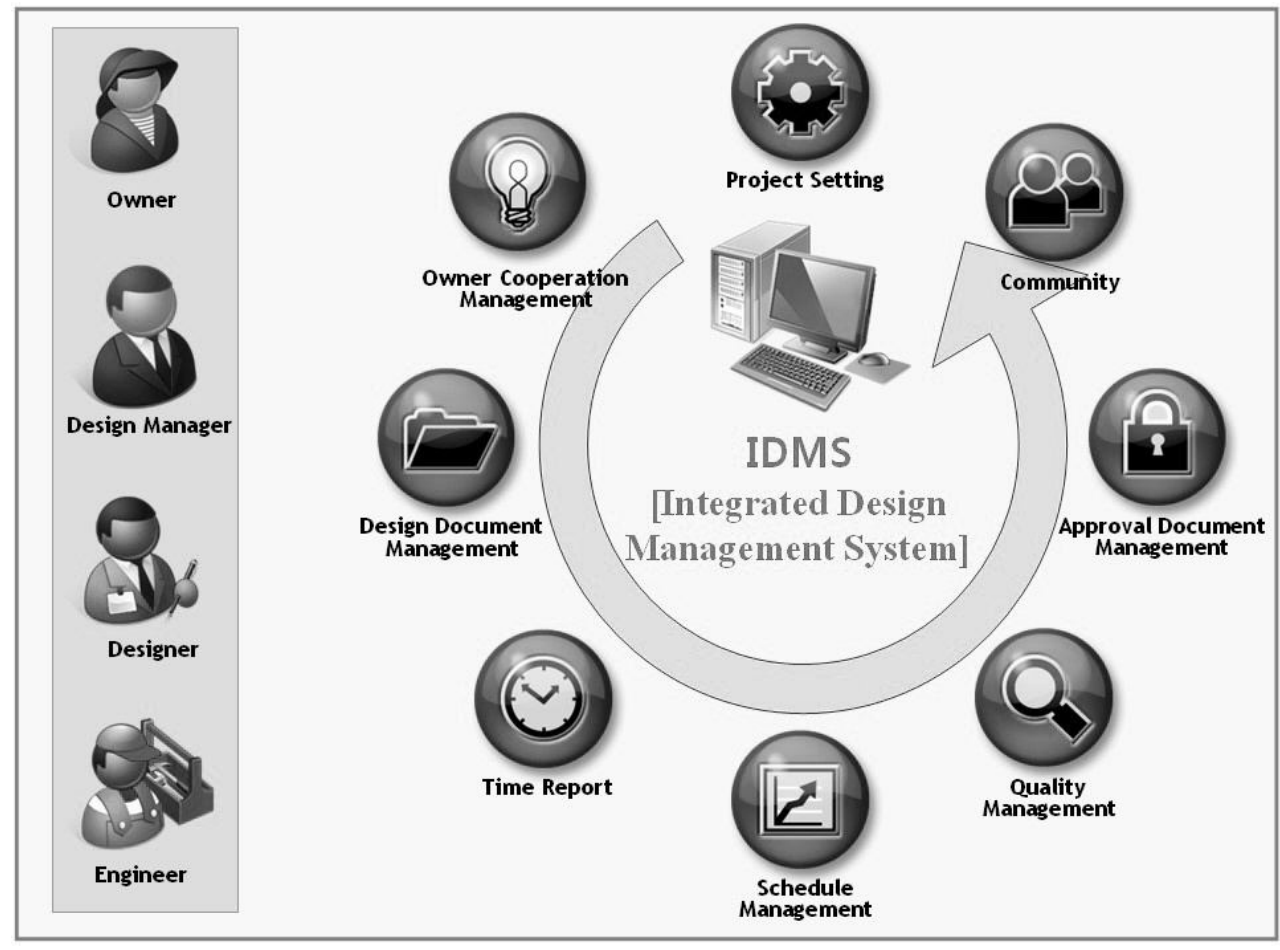

Figure 1: Functional Composition of IDMS

As shown in Project Setting module (the left part of Fig. 2), design work process, which consists of (1) Design Work, (2) Approval Work and (3) Engineering Work, could be established based on the project characteristics, design firms and design teams. According to the established design work process, other setting elements of Project Setting module in IDMS could be redefined, which includes (7) Person in charge, (8) Weight, (9) Checklist, (10) Cooperation document and (11) Plan for the schedule by design work. These setting results would be intimately connected to design management indices of IDMS, which includes [1] Design Document Management, [2] Schedule Management, [3] Time report, [4] Quality Management and [5] Approval Document Management as shown in Fig. 3. In addition, Approval document would be entered into the relevant cabinet based on a relation with (4) Design Document, (5) Engineering Document and (6) Attached Document. 
As shown in Design Document Management module (the right part of Fig. 2), design document and engineering document yielded during the actual design process would be uploaded to IDMS according to the results established in Project Setting module. For example, in case of design document, all product of design work would be uploaded according to the document breakdown structure established in (1) Design Work of Project Setting module. Approval document might be also distributed according to the approval standards established in (4) Design Document of Project Setting module. As such a process, (2)Approval Work, (3)Engineering Work, (5)Engineering Document and (6) Attached Document would be applied to IDMS.

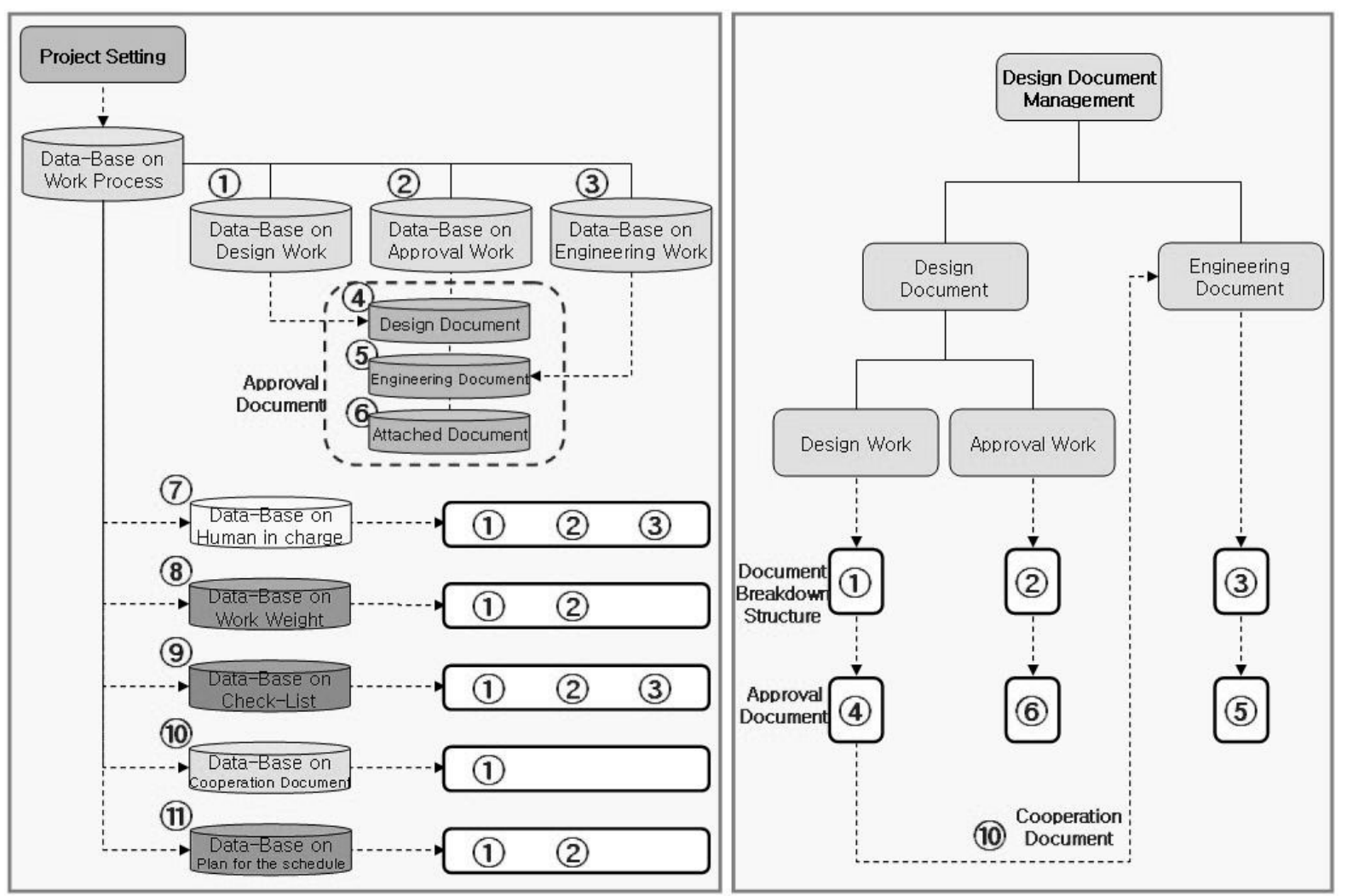

Figure 2: System Architecture and Relationship - 1

As shown in Fig. 3, the system architecture and relationship of IDMS was designed for users to easily access to the system. In other words, as stakeholders merely manage all the design work products in [1] Design Document Management module, the design management indices that are included in [2] Schedule Management, [3] Time Report, [4] Quality Management and [5] Approval Document Management, can be systematically managed in IDMS. The detailed description is as follows:

- Part [1] : This is a module to manage the design document, which has been already explained in the right part of Fig. 2.

- Part [2] : This is a module to manage the design schedule. As the user uploads the design document in [1] Design Document Management module, IDMS creates the schedule 
management indices such as the master schedule, the design schedule and the approval schedule, which is deduced according to the standards established in (8) Weight and (11) Plan for the schedule by design work of Project Setting module.

- Part [3] : This is a module to manage the commitment of time by person in charge. As the user uploads the design document in [1] Design Document Management module and enters the commitment of time by person in charge, IDMS creates the statistics of commitment of time, which is deduced according to the standards established in (7) Person in charge by design work of Project Setting module.

- Part [4] : This is a module to manage the design quality. As the user uploads the design document and reviews the checklist in [1] Design Document Management module, IDMS creates the quality management indices on the owner requirement, the design document and the engineering document, which is deduced according to the standards established in

(9) Checklist by design work of Project Setting module.

- Part [5] : This is a module to manage the approval document. As the user uploads the design and engineering document in [1] Design Document Management module, IDMS distributes them to the proper cabinet among the design document, the engineering document and the attached document, which is deduced according to the standards established in (4) Design Document, (5) Engineering Document and (6) Attached Document of Project Setting module.

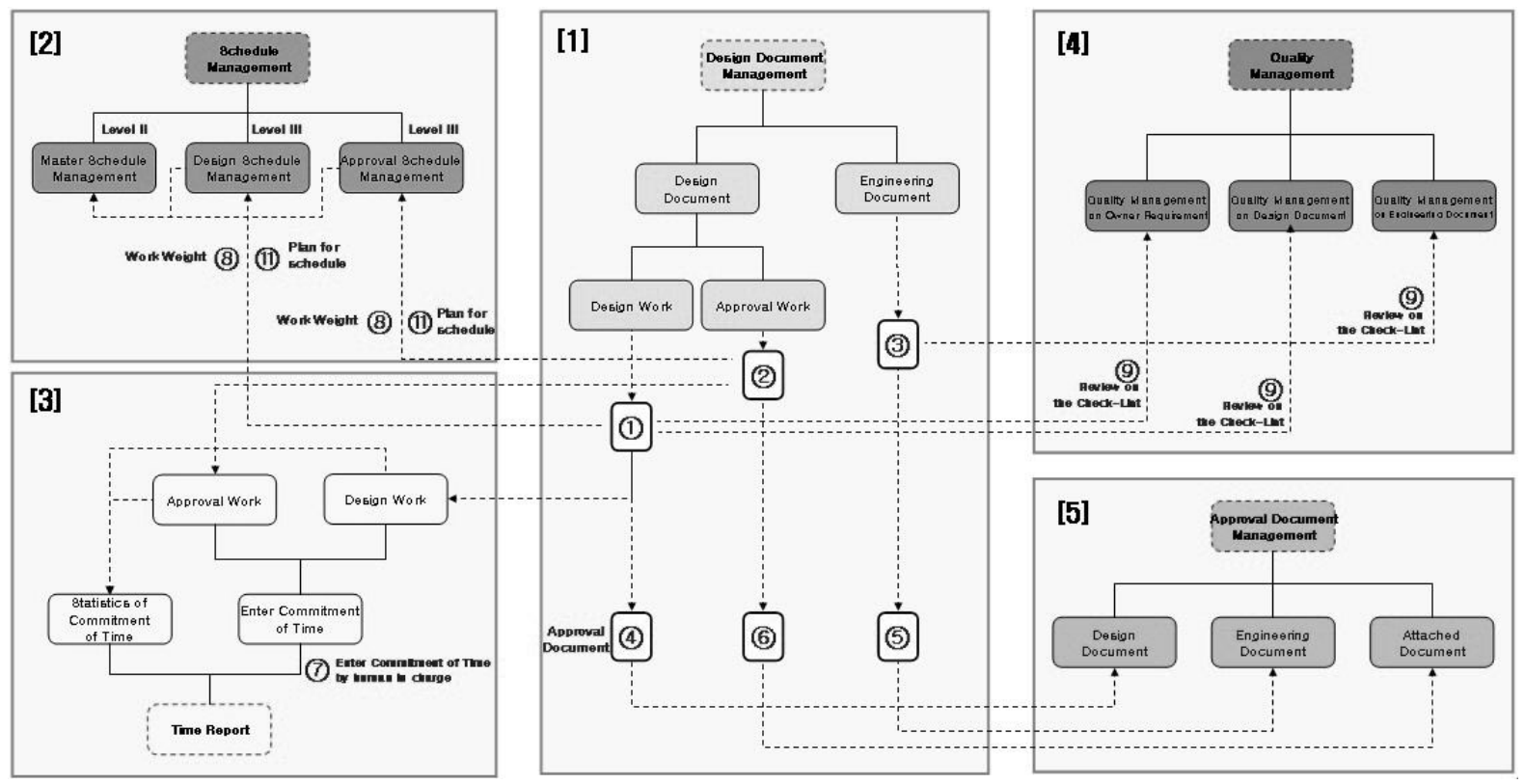

Figure 3: System Architecture and Relationship - 2 


\section{SYSTEMIZATION OF IDMS}

\section{Considerations for systemization}

As mentioned above, IDMS includes various functions for design management and can be accessed by several stakeholders. Thus, it is necessary to develop the process and standards for design management as a web-based system. The following are the three factors to be considered for systemization.

- Integration of several design management elements;

- Cooperation structure between various stakeholders;

- Flexibility for acceptance of the changes of construction environment;

\section{Graphical user interface (GUI)}

As shown in Fig. 4 to Fig. 9, the GUI of IDMS is designed for users to have an easy access. The detailed descriptions of IDMS are as follow:

- As shown in Fig. 4, Project Setting module is a phase in which the system is initialized to perform the design management. Users can configure the design work process according to the project characteristics, other settings such as person in charge, weight, checklist, cooperation document and plan for the schedule are configured for this context.

- As shown in Fig. 5, Design Document Management module is a phase in which the design documents are uploaded according to document breakdown structure set in Project Setting module. As the design documents are uploaded to IDMS, design management indices such as manpower, schedule, quality and approval are created automatically.

- As shown in Fig. 6 to Fig. 9, Design management indices are systematically deduced from IDMS. Design manager or designer can grasp the situation, if necessary, establish some measures which act effectively on the process of design management. After a project has been completed, these results can be used to prepare a new project as a reference.

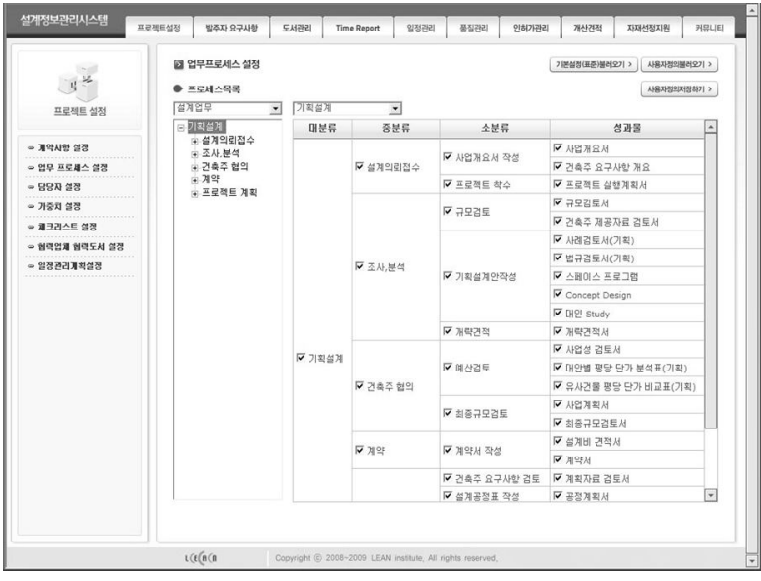

Figure 4: GUI for Project Setting module

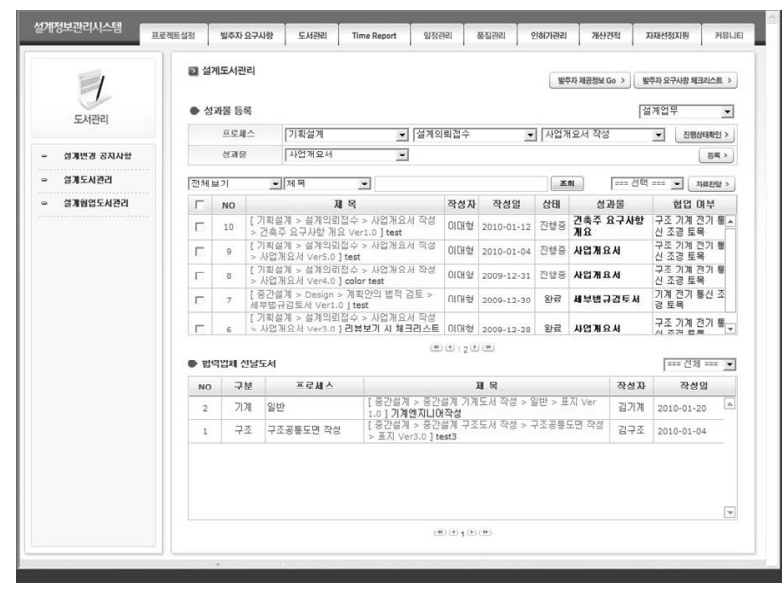

Figure 5: GUI for Design Document Mgt. module 


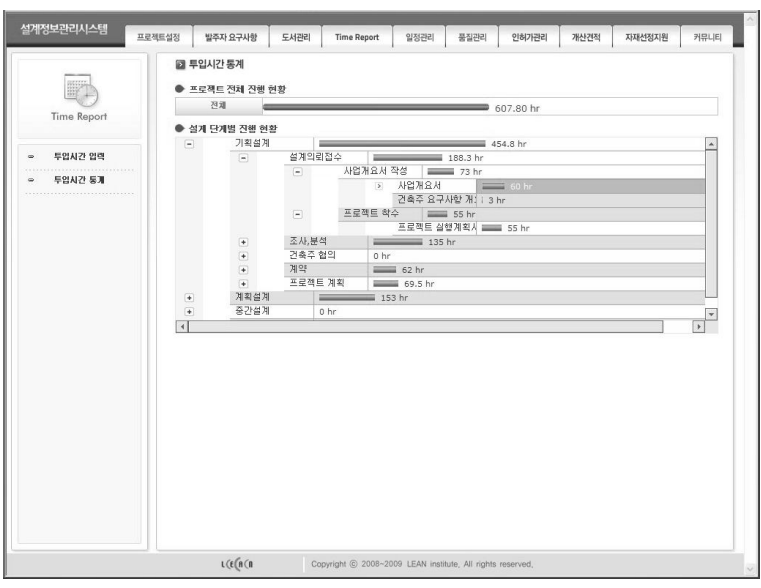

Figure 6: GUI for Time Report module

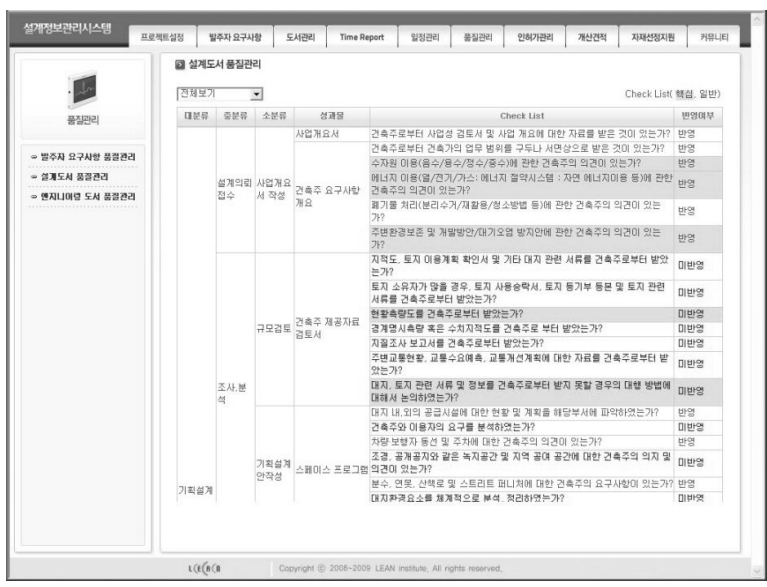

Figure 8: GUI for Quality Mgt. module

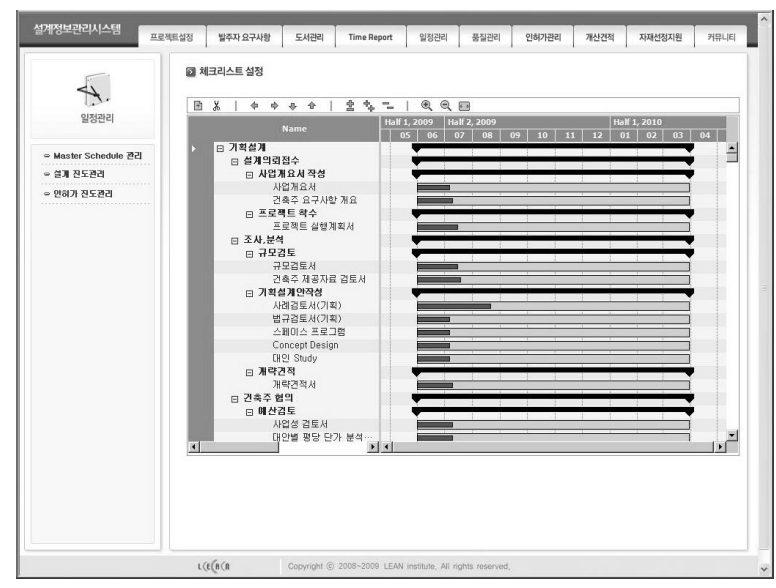

Figure 7: GUI for Schedule Mgt. module

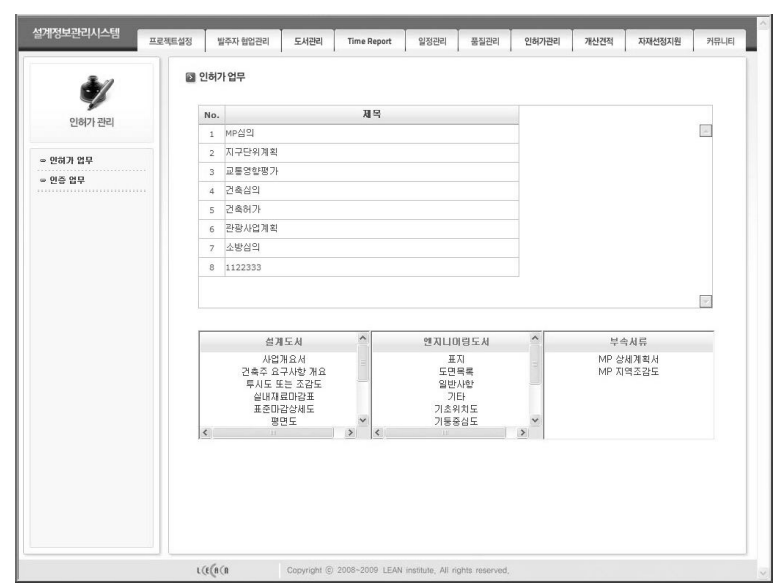

Figure 9: GUI for Approval Mgt. module

\section{RESULTS AND DISCUSSION}

\section{Difference between IDMS and conventional system}

IDMS developed in this study has distinctive characteristics in comparison with the conventional design management system.

First, IDMS is developed to integrate several design management indices such as manpower, schedule, quality and approval. In the existing environment, systematic design management process was not implemented and design work completely depended on the abilities and experiences of each architect rather than organizational and cooperative system. Although there are several systems for managing design process, they are just developed similar to the function of web-hard, which is to gather information on the design document. On the contrary, IDMS was developed to reflect all function of design management as a web-based system. As design documentation are uploaded on IDMS, design management indices such as manpower, schedule, quality and approval have been created automatically. 
Second, IDMS was developed to improve interoperable communication among stakeholders by developing tools and guidance for their use. For example, checklist for owner requirement was applied to IDMS to improve and systemize owner requirement management. Also, exchange requirement and process according to the flow of information were adapted to IDMS for creating a collaborative environment between designer and engineer. It could help interference check between design and engineering document easily. Finally, change orders occurred from owner or designer were opened and controlled in IDMS, which makes communication among stakeholders more efficient

Third, IDMS provides flexibility for rapidly responding to changes in the project characteristics, design firms and design teams. In other words, IDMS is developed flexible enough to reconfigure the definition of design work process and to adapt these configuration changes with considering other modules of IDMS related to the design management indices such as manpower, schedule, quality and approval. The configuration of IDMS was set up based on the current design process, which can be adjusted flexibly according to the changes of construction environment.

\section{Direction for sustainable development of IDMS}

IDMS is developed to be applied to current 2D design process. However, the application of BIM-based design process has recently increased and will spread out further. Thus, new directions for sustainable development of IDMS need to be considered.

First, design work process needs to be redefined. There are four steps in 2D design process: 1) Pre-design, 2) Schematic Design, 3) Design Development, 4) Construction Documents. However, BIM-based design process consists of four steps that are different from 2D design process: 1) Conceptualization, 2) Criteria Design, 3) Detailed Design, 4) Implementation Documents.

Second, the application of BIM-based design process does not only change design work process, but also accompany additional changes. That is to say, IDMS will accept the changes for composing the design team to carry out the design work, analyzing the details of design work and arranging the role-sharing and collaboration procedure along with the changes of design work process.

Third, IDMS needs to accept the advantage of BIM-based design. For example, BIM-based design process systematically provides structural analysis, energy analysis, 4D planning \& control, quantity take-off \& estimation besides interference check. In other words, design management in BIM-based design process can be carried out more than the current 2D design process.

Fourth, IDMS not only needs to keep current design management system, but also accept future changes from BIM-based design process. Although BIM-based design process provides various useful functions, it could not be developed in web-based system due to capacity limitations. Also, 2D design documents should be managed for the government's approval. Thus, IDMS needs to adapt to changes for the sustainable development. 


\section{CONCLUSION}

This study developed Integrated Design Management System (IDMS) based on the definitions of both design information and the relationship between stakeholders. It consists of (i) module for setting standards including design work process, weight and checklist, (ii) module for managing cooperation work between stakeholders, (iii) module for managing design documents and (iv) module for presenting design management indices.

This study explains the following six subjects in detail: (i) System architecture and relationship, (ii) Systemization of IDMS, (iii) Difference between IDMS and Conventional System, (iv) Direction for sustainable development of IDMS. It makes other researchers well understand the framework of IDMS and help study into a future research in depth.

IDMS is designed to integrate several design management indices, improve interoperable communication and accept flexibility for responding rapidly to changes. It is expected to support stakeholders in charge of carrying out design works. Since IDMS is developed as a web-based system, stakeholders can systematically, quickly and easily utilize it.

\section{ACKNOWLEDGMENT}

The authors would like to acknowledge the support for this research from the Korean Ministry of Construction and Transportation, Research Project 05 CIT D05-01.

\section{REFERENCES}

Austin, S., Andrew, B., Baizhan, L., and Paul., W (1999) Analytical Design Planning Technique : a model of the detailed building design process. Design Studies 20. 279-296.

Bae, J.I., Shin, J.W., and Gwon, O.G (2006) A Suggestion for Design Process Improvement to Develop a Design Management Model. Korea Institute of Construction Engineering and Management, 7(6), 90-98.

Choo, H.J., Hammond, J., Tommelein, I.D., Austin, S., and Ballard, G. (2004). DePlan: A tool for integrated design management. Automation in Construction, 13, 313-326.

Koo, C.W. (2009), Understanding of the Integrated Design Management. $19^{\text {th }}$ Issue Report, Construction Strategy Research Institute, HanmiParsons Co., Ltd.

Korea Institute of Construction Technology (KICT) (2000), Design Management Practices in Korean.

Shin, J.W., Ryu, H.G, and Lee, D.R (2007). Information-oriented Design Management System Prototype. $2^{\text {nd }}$ International Conference World of Construction Project Management.

The American Institute of Architects (AIA) (2007a). Integrated Project Delivery : A Guide.

The American Institute of Architects (AIA) (2007b). Integrated Project Delivery: A Working Definition.

Tzortzopoulos, P., and Formoso, C.T (1999) Considerations on Application of Lean Construction Principles to Design Management. International Group for Lean Construction-7. 